\title{
THE MORPHOLOGY OF MYCOBACTERIUM LEPRAE
}

\author{
H. C. ie Souza-Araujo, m.D., Dr. P.H.
}

Instituto Oswaldo Cruz, Rio de Janeiro

\section{Introduction}

The morphology of $M$. leprae as revealed by classical optics was described by $F$. Löhnis' ${ }^{1}$ after a review of the literature from 1838 to 1918 , and completed in 1923 by A. Paldrock ${ }^{2}$, but electron and phase contrast microscopy brought considerable progress. This paper is a confirmation of that presented to the VI International Congress of Leprology in October, 19533.

\section{Materials and Methods}

For this study we used serum obtained from the skin of various lesions of erythema nodosum leprosum (hereinafter called ENL) of a female patient of white race, of 44 years of age, who was clinically $\mathrm{L}_{2} \mathrm{~N}_{2}$ type and while on sulphone treatment had twice a year lepra reactions of ENL type which were difficult to control. We also used fresh suspensions in sterile distilled water of triturated lepromas of human and murine origin, as also human lepromin and lepromas kept in $40 \%$ glycerin in water for a few days. For phase contrast microscopy we used two drops of fresh suspensions of lepromas between common glasco slides covered with thin slides of the kind used for sections. For electron microscopy we used the same suspensions after they had been centrifuged twice and filtered through sterile gauze: they were then placed on collodium film on a metallic grid (a mesh of stainless steel wire) and dried in an incubator at $40^{\circ} \mathrm{C}$., and then placed in the electron microscope, which was RCA, type EMU-2C, 50,000 volts. The electron micrographs were taken at a magnification of 4,000 to $7,800 \mathrm{X}$.

\section{Structure of M. leprae}

See Plates 1 to 4. (The electron micrographs of Plate 1 were made by Dr. Penna Franca, and those of Plates 2, 3, and 4 by Dr. Hans Muth, Chief of the Physical Research Laboratory of the Instituto Oswaldo Cruz. The author is greatly indebted to these two colleagues).

\section{PLATE 1}

Three electron micrographs of a fresh suspension of leproma from a F. aet. 16 years, before any anti-leprosy treatment was given. No. I shows a compact mass of bacilli surrounded by a well-defined sheet of gloea, and two free gramules. No. 2 shows two bundles of bacilli in palisade, also surrounded by gloea. No. 3 shows $t$ wo bacilli, one of which is homogeneous, with a clear sheet of gloea double the usual size. All the bacilli were carbonized by the electron beam, and hence became opaque and appear as compact black masses, and the gloea became white, coagulated by the electron bombardment. All three figures suggest the fusion of the gloea of each bacillus. 


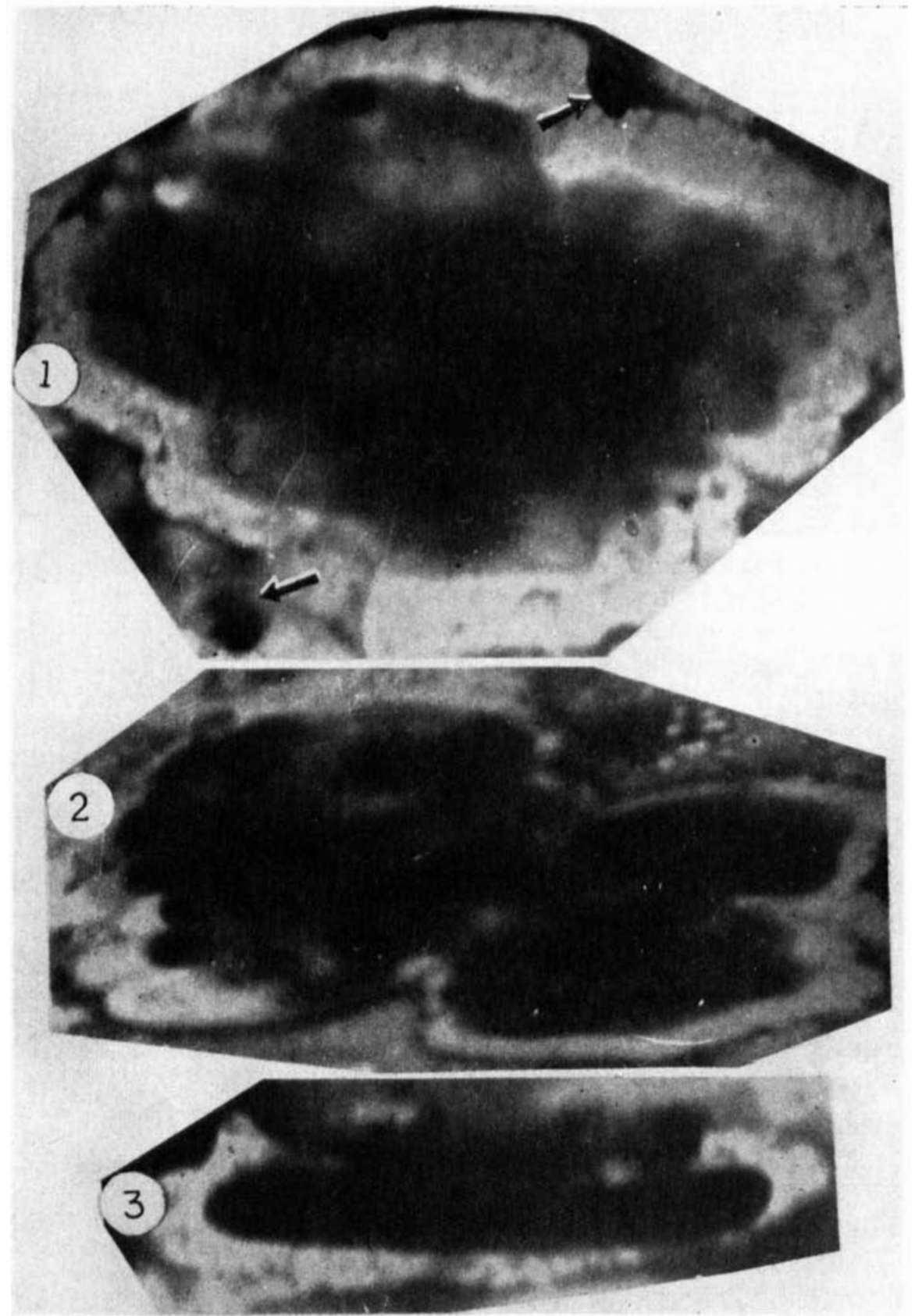

Plate I Morphology of Mycobacterium leprae. Magnification 22,500 x. 

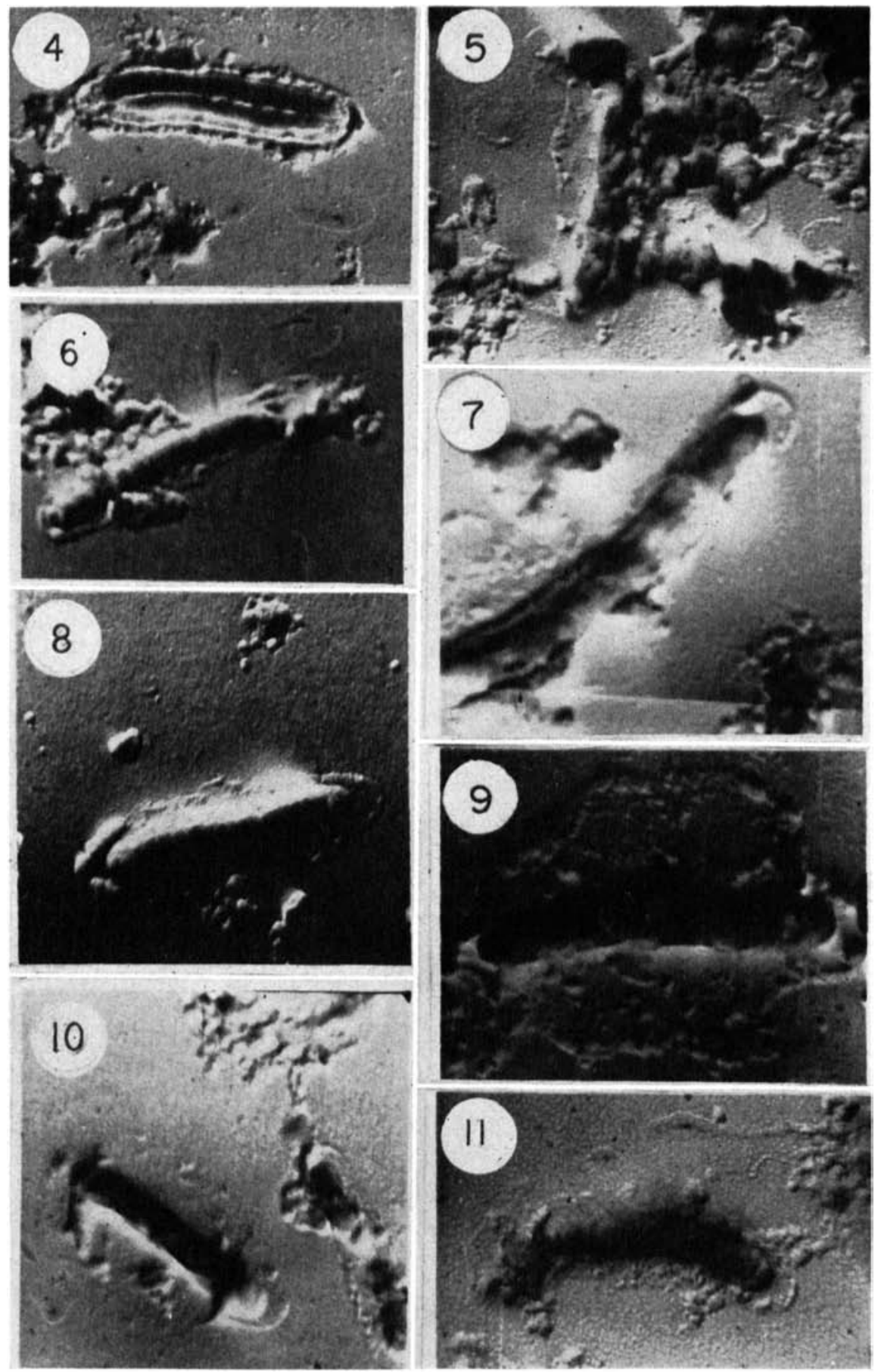

Plate 2

Leproma in 40\% glycerin-water. Shaded. 

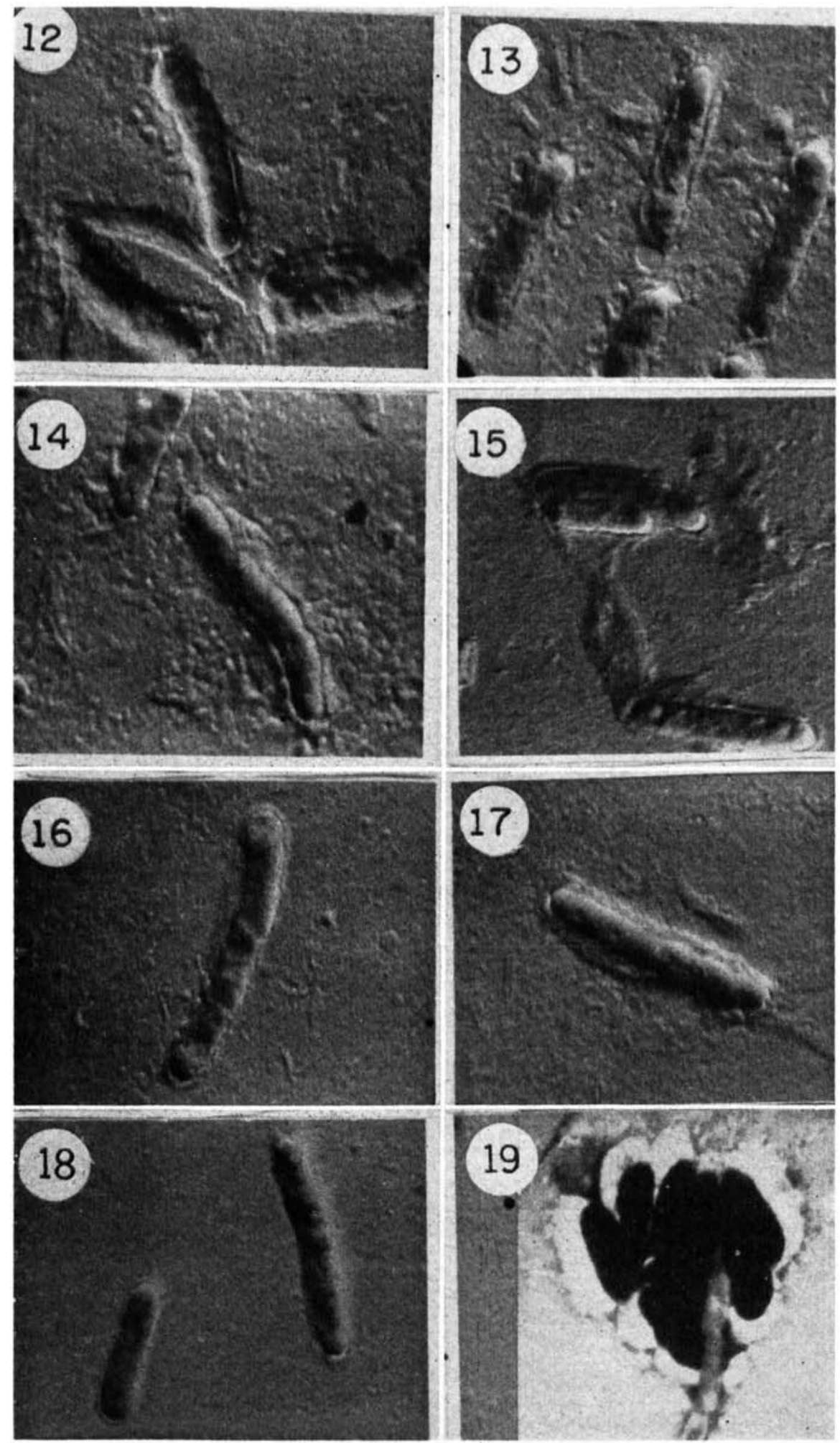

Plate 3

\section{Stefansk}




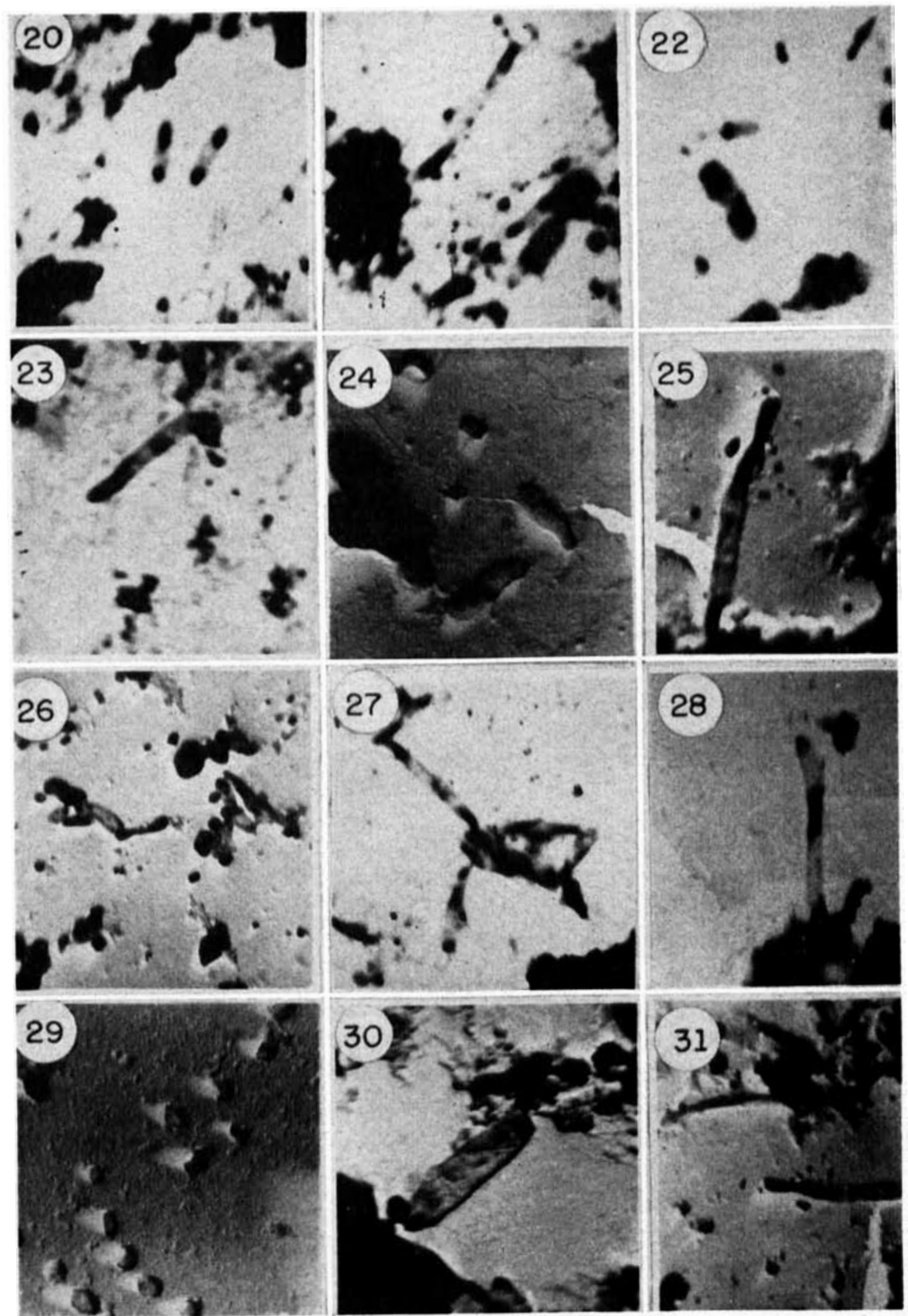

Plate 4

Human Lepromin

Magnification 3,900 to 4,720 x 
PLATE 2

Nine electron-micrographs of 4,700 to 7,800 $x$, of a fresh suspension of human leproma kept in $40 \%$ glycerin and water for ten days. After being put on collodium film on the stainless steel wire mesh the material was dried in incubation at $40^{\circ} \mathrm{C}$. and shaded by jets of chromium vapour. All bacilli look damaged .The membrane of No. 4 appears well separated from the cytoplasm but fringed. The gloea belonging to Figs. 8 to 11 looks as if dissolved, and is irregularly spread. Figs. 5 and 9 look like a fusion. There are widespread granular particles (microspares?).

Magnification 4,700 to $7,800 x$.

\section{PLATE 3}

Seven electron micrographs of a suspension from an inguinal tumour of Mus musculus niger at 16 days after inoculation with rat leprosy bacilli. The preparation was shaded with chromium and shows different aspects of the Stefansky bacillus, of which the morphology (Figs. 12 to 18) is similar to that of the Hansen bacillus. All bacilli show their membranes but none their gloea. For this suspension the Nadi Test was negative, as triphenol tetrazolium was not reduced, proving that the bacillus is pathogenic. Fig. 19 shows a compact mass of six or more bacilli from a leproma from a white rat (at magnification 6,300 x). These bacilli look black, unshadowed, with a surrounding white gloea as of the Hansen bacillus of Plate 1. Magnification 6,300 $x$.

\section{PLATE 4}

Twelve electron micrographs of fresh human lepromin prepared by the MitsudaHayashi method (1933), showing pleomorphic elements, most of them disintegrated by the heat of boiling and electronic bombard ment, and without shadowing. Fig. 20 shows two normal bipolar bacilli, without gloea, destroyed by boiling. Fig. 29 shows twelve well-defined free granules at magnification 4,780x. Most of the figs. show remnants of bacilli and granules. Such a lepromin, stained by Ziehl-Neelsen method and examined by ordinary microscope shows few nor mal bacilli, with disintegrated globi and acidfast filaments and granules of different sizes, fuchsinophil dust and dark-blue nuclear detritus.

Magnification 3,900 to 4,780 $x$.

(a) The Cell Membrane. It is by phase contrast microscopy that that we see most clearly the cell membrane of $M$. leprae. In the bacillary form of $M$. leprae the membrane circumscribes the cytoplasm, which seems liquid, with granules in constant movement. In electron micrographs the aspect of the membrane changes according to whether the material was shadowed by chromium or not.

(b) Gloea. This vitrous mucous material described by Unna and Lutz in 1886 was considered by Jeanselme as characteristic of the bacillus of leprosy. It cannot be stained by the ordinary methods and by phase contrast appears as a clear halo around the human or murine leprosy bacilli. By electron micrography of unshadowed material the gloea appears as a white sheet enclosing the bacilli, whether isolated or in masses. Jeanselme says " . . . les substances grasses de la couche profonde de la glée sont des corps isotropes, homogènes, lipoides". ${ }^{4}$

(c) Metachromatic granules. Since 1953 the mycobacterial metachromatic granules are being called mitochondria (Mudd et al.), which means "thread granules" according to Stedman's medical dictionary, synonymous with "coccothrix", the name given by A. Lutz in $1886^{5}$ for lepra and tuberculosis bacilli. The chemical constitution of the metachromatic granules is still undecided. F. Scanga ${ }^{6}$ says that they represent a carbohydrate reserve and are 
especially present in spore-bearing bacilli: from the biological point of view the glycogen granules are perhaps to be considered as a source of energy which the cell uses at special times. A. Paldrock? says ". . . l'acide nucléique libre (selon toute probabilité analogue à la volutive) se trouve dans les granulations, tandis que, dans les substances qui les enveloppent et qui constituent les bâtonnets, prédominent les nucléides et les nucléo-protéides”. Max and Woith say that such granules are the reservoir of life energy and of the virulence of bacteria, and I myself think ${ }^{8}$, as I said in 1943, that they are the original elements of mycobacteria, the cause of tuberculoid leprosy, and the cause of many relapses in patients who had reached clinical arrest of the disease. In tuberculoid leprosy, when we find granules in skin lesions, or later on masses or morulae of granules, there is a liability to the mutation into lepromatous leprosy.

(d) $M$. leprae by ordinary microscopy is best studied in the contents of the intracutaneous nodules of the ENL lesions rather than in the suspensions of lepromatous tissue, and the staining is by Ziehl-Neelsen or Fontes methods. The smear stained by ZiehlNeelsen method shows a formidable quantity of acidfast bacilli lying in big masses, globi, and clubs intra- or extracellularly. The dense masses of bacilli stain well at the periphery and centrally there are pale rose filaments or detritus of bacilli. There are sometimes bacillary balls which are 10 to 15 times larger than the common globi, and have a dense peripheral sheet of bacilli, the centre being empty, or containing remnants of segmented bacilli. By the Fontes staining method the isolated bacilli show beautiful dark-stained granules of various size and position inside the bacilli. In general the central granules are larger than the terminal ones, and from these larger granules gemmules or branching may develop.

Repeated examinations by electron microscopy have confirmed for us what we described before ${ }^{3}$, that $M$. leprae shows a membrane, and the halo of gloea which becomes more visible when it surrounds the globi or palisades of bacilli; there are also free granules of various sizes and external granules bound up with the membrane and sometimes forming branches or gemmules. In phase contrast microscopy at $400 \mathrm{X}$ the leprosy bacillus shows free granules which have an intense rotatory movement, and there are granular bacilli which have a screwing, skipping, or stroke motion, which produces a slow progression. All the bacilli are surrounded by membrane and gloea, and the cytoplasm seems to be liquid or semi-liquid, because the internal granules change places, from one end to another. Sometimes the bacilli form into a ball. Sometimes the larger granule in a bacillus prolapses as a gemmule or branch, and finally detaches itself and progresses with a very rapid rotatory movement: later on it acquires a peduncle and grows until it takes the form of a comet or musical note and finally becomes a new bacillus. Not all the granules produce 
new bacilli; most of them are sterile as are most of the seeds of any plant.

(e) The Stefansky bacillus. I have shown that the laboratory animal most sensitive to the Stefansky bacillus is the black mouse ${ }^{9}$. A suspension of nodular material or abscess from this mouse, taken a few weeks after the inoculation of the infection, and stained either by Ziehl-Neelsen or Fontes methods, shows that the Stefansky bacillus is thinner than $M$. leprae and its granules smaller and more regular. The globi are sometimes enormous.

Electron microscopy of fresh rat leproma shows their bacilli, a few homogeneous and the most granular, and the granules are smaller and more regular than those of $M$. leprae. The bacilli also show the membrane and the halo of gloea in unshadowed material. Owing to the electron bombardment both the Hansen and Stefansky bacilli are much altered in structure, so that centrally and terminally black bars or granules of chromatin condensation or carbonized globulin appear.

By phase contrast the Stefansky bacilli show as rods with one, two (bipolar), three, or more internal small granules, which show the same movements as the granules in M. leprae. The globi do not move, but the free bacilli around them indulge in normal movement. At $1000 \mathrm{X}$ magnification the examination is less satisfactory than at $400 \mathrm{X}$. The addition of formol solution to the preparation suppresses all movements and the material becomes more suitable for the study of the static morphology.

\section{Discussion}

Electron and phase contrast microscopy have greatly advanced our knowledge of the morphology of $M$. leprae but we still have much to learn. More studies are needed of material from all types and groups of leprosy, and especially from dimorphous or borderline cases, and thin sections of florid lepromatous lesions, and lesions of ENL.

\section{Summary}

Both phase contrast and electron microscopy have been used by the author to study the bacillary morphology in human and rat leprosy. Phase contrast was best for revealing the cell membrane, the apparently liquid cytoplasmic contents, and the presence of granules in constant movement: also the gloea appears as a clear halo. The metachromatic granules are considered to be viable and the means of perpetuating the life history of the bacillus. By phase contrast also the granular bacilli were seen to have a slow progressive motion, and sometimes a larger granule prolapsed and extruded and progressed with a rapid rotatory movement, and acquired a peduncle and later a comet form and finally became a new bacillus. 
Electron microscopy confirms the membrane, gloea, and granules, both internal and free, and in gemmule form. The Stefansky bacillus is thinner than $M$. leprae and its granules are smaller and more regular, and membrane and gloea are also clearly seen. By phase contrast the granules and the bacilli are also seen to have movements similar to $M$. leprae.

\section{References}

1. LöHNIS, F. Studies upon life cycles of the bacteria. Nat. Acad. Sci. Vol. XVI. 2nd Memoir, Washington, 1922.

2. Paldrock, A. Rapport III Conf. Internat, de la Lèpre, 1924, p. 138.

3. Souza-Araujo, H. C. DE. Morphology of M. leprae hominis and M.l. muris, based on electron and phase contrast microscopy. Memorias Inst. Osw. Cruz, Tomo 53, 1955, pp. 395/6.

4. JeANSElme, Ed. Le Lèpre, 1934, p. 123.

5. Lutz. Ad. Zur Morphologie des Mikroorganismus der Lepra. Dermatologische Studien, Edited by P. G. Unna, 1886, No. 1.

6. Scanga, Franco. La Cellula Batterica, Il Pensiero Scientifico, Roma, 1954.

7. Paldrock, A. Les Microbes de la Lèpre contiennent des acides nucléiques libres et fixés. Rapport III Conf. Internat. de la Lèpre. 1924, p. 141.

8. Souza-Araujo, H. C. DE. A Lepra Tuberculoide, ou melhor, a Lesão Tuberculoide na Lepra, representa uma fase de transição desta Dermatose e não uma forma clínica autônoma.

Novos achados bacterioscópicos na linfa subcutanea de leprosos. Memorias Inst. Osw. Cruz. T.39 (1) 1943. pp. 77-96.

9. Souza-Araujo, H. C. DE, Rat leprosy: Susceptibility of the Black Mouse (American Race) to the Stefansky Bacillus. Preliminary Report with 4 figures. International Journal of Leprosy, Vol. 18 (1). Jan. 1950. pp. 49-52. 